\title{
Regulación de entrada: Experiencia peruana sobre prohibiciones y restricciones para el
} acceso al mercado( ${ }^{(* *)}$

\section{Entry regulation: Peruvian experience on prohibitions and restrictions to the market access}

\begin{abstract}
Resumen: En este artículo, se explica cómo funciona la regulación de entrada estableciendo prohibiciones o impedimentos para la entrada de nuevos competidores (efectos absolutos) o limitaciones al número de operadores que pueden actuar en el mercado (efectos relativos). Asimismo, se evalúa si existe espacio para la regulación de entrada dentro del marco legal peruano, que garantiza la libre iniciativa privada y prohíbe el establecimiento de monopolios legales. Finalmente, a través de diversos casos concretos peruanos, se explica los escenarios en que la regulación de entrada, ya sea con efectos absolutos o relativos, puede tener una justificación válida y razonable, así como otros supuestos en que ese tipo de medidas carecen de sustento y ocasionan efectos negativos para el mercado y las opciones de elección de los consumidores.
\end{abstract}

Palabras Clave: Regulación de Entrada - Monopolios Legales - Barreras y Restricciones de Acceso al Mercado

\begin{abstract}
This article addresses the way entry regulation works, creating prohibitions for the access of new competitors to markets (absolute effects) or limitations to the number of providers that can operate in the market (relative effects). The paper also assesses whether Peruvian legal framework allows for entry regulation, because it guarantees free private initiative and prohibits the creation of legal monopolies. Finally, several examples from Peruvian experience are used to explain the scenarios were entry regulation can have suitable and reasonable justification, as
\end{abstract}

$\left(^{*}\right.$ Abogado por la Pontificia Universidad Católica del Perú. Magíster en Regulación de Servicios Públicos por la London School of Economics and Political Science. Profesor de Facultades de Derecho y Programas de Post Grado de la Pontificia Universidad Católica del Perú, Universidad ESAN, Universidad del Pacífico y Universidad Peruana de Ciencias Aplicadas. Socio de Bullard, Falla, Ezcurra Abogados. Correo electrónico: equintana@bullardabogados.pe

${ }^{* *}$ Abogada por la Pontificia Universidad Católica del Perú. Magíster en Derecho por la Universidad de Michigan. Miembro del Equipo de Políticas de Competencia de la Práctica de Comercio y Competitividad del Banco Mundial. Correo electrónico: villaran.lj@pucp.edu.pe

${ }^{* * *}$ Nota del Editor: El artículo fue recibido el 15 de noviembre de 2016 y aprobada su publicación el 17 de diciembre del mismo año. 


\section{Regulación de Entrada: Experiencia peruana sobre prohibiciones y restricciones para el acceso al mercado Entry regulation: Peruvian experience on prohibitions and restrictions to the market access}

well as other scenarios were such measures lack support and cause negative effects on the market and consumer choices.

Keywords: Entry Regulation - Legal Monopolies - Barriers and Restrictions to Market Access

\section{Introducción}

El Perú es una economía social de mercado que tiene su motor principal en la libertad de empresa. El marco legal garantiza la libre iniciativa privada, señalando que toda persona tiene derecho a dedicarse a la actividad económica de su preferencia. Para que esto se materialice es necesario que los agentes económicos puedan ingresar al mercado; es decir, dedicarse a cualquier actividad productiva y comercial que deseen, sin verse impedidos o limitados por decisiones del Estado.

No obstante, en los hechos, ciertas actividades económicas de suma relevancia para la población y para el país en general solo son realizadas por un agente, es decir, hay bienes o servicios que solo ofrece un proveedor sin que ingresen nuevos ofertantes. Puede mencionarse algunas como la distribución de gas natural en las ciudades de Ica o Lima, los servicios del Aeropuerto Internacional Jorge Chávez, la distribución de electricidad para los hogares ubicados en ciudades de la costa, sierra o selva, o el servicio de telefonía de larga distancia que por 5 años estuvo reservado a un solo operador. La interrogante es si no existen empresas interesadas en brindar los mismos servicios, en particular, atender a algunos segmentos de consumidores, como aquellos dispuestos a pagar más por el servicio (los más rentables) o aquellos que presentan consumos más intensivos (mayor volumen de venta).

Asimismo, hay otras actividades también de relevancia que solo son realizadas por un número limitado de agentes. Por ejemplo, por muchos años, solo hubo 3 o máximo 4 empresas operadoras de servicios de telefonía móvil. Nuevamente, la interrogante es si no existen otros inversionistas interesados y en capacidad de brindar tales servicios.

Si la respuesta a dichas interrogantes fuera un simple no, el tema no tendría mayor relevancia jurídica, puesto que la ausencia de otros proveedores se debería precisamente a que en ejercicio de la libre iniciativa privada los agentes han tomado la decisión de no participar en dichas actividades económicas.

Pero lo cierto es que existen normas legales o decisiones de entidades del Estado que crean impedimentos que dan lugar a las exclusividades antes mencionadas o establecen limitaciones que reducen el número de agentes autorizados para realizar cierta actividad. Estas normas legales o decisiones gubernamentales que ponen límites a la libre iniciativa privada en cuanto al número de agentes que pueden realizar una actividad económica, se denominan regulación de entrada.

La regulación de entrada reduce ampliamente la libre iniciativa privada, por lo que debe ser cuidadosamente utilizada, al ser un instrumento regulador muy intrusivo. Para ello, debe definirse con mesura los ámbitos en que puede estar justificada y su horizonte temporal.

A continuación, se explica y analiza los alcances de la regulación de entrada, cómo funciona a través de prohibiciones al ingreso de competidores o mediante restricciones al número de proveedores habilitados a participar en cierto mercado. Asimismo, se explica las razones que suelen justificar la introducción de algún tipo de regulación de entrada y los efectos perjudiciales que pueden ocasionar si es mal diseñada o implementada. Seguidamente, se plantea e interpreta el marco legal peruano aplicable a las restricciones que impiden o limitan la entrada de agentes económicos al mercado, identificando condiciones legales básicas que deben ser observadas para establecer la regulación de entrada en el país.

Luego de ello, se presentan diversos casos peruanos que demuestran cómo se aplica y 


\section{Eduardo Quintana Sánchez y Lucia Villarán}

funciona la regulación de entrada, distinguiéndola según tenga efectos absolutos al impedir el ingreso de nuevos agentes o relativos al limitar la entrada a un número específico de proveedores. También se comentan mecanismos que si bien no controlan la entrada sí restringen la capacidad de expansión de ciertos agentes que ya se encuentran operando en el mercado. Finalmente, se presentan algunos ejemplos en los que la regulación de entrada existente no tiene justificación y pueden ocasionar efectos indeseados.

\section{Regulación de entrada como instrumento regulatorio ${ }^{(1)}$}

Una definición clásica de la regulación la asimila con la facultad del Estado, en ejercicio de su ius imperium, de imponer y hacer cumplir reglas de comportamiento a los administrados con el objetivo de controlar fallas de mercado. Paralelamente, una clasificación bastante generalizada de la regulación la distingue en económica y social, considerando las distintas fallas de mercado que se trata de controlar mediante la regulación.

La regulación económica tiene como objetivo enfrentar situaciones de falta de competencia en los mercados, siendo el monopolio natural el supuesto clásico que justifica este tipo de regulación. En este supuesto, la regulación económica recurre a instrumentos que permitan simular los resultados de un mercado competitivo, tales como la regulación del precio y la calidad de los bienes. Asimismo, cuando se opta por elegir a un solo agente para realizar cierta actividad económica, la regulación económica ofrece instrumentos de competencia por el mercado (por ejemplo, concursos) para elegir al postor más eficiente para realizar dicha actividad. Las normas que prohíben y sancionan comportamientos anticompetitivos (acuerdos entre competidores y actos de abuso de posición de dominio) también califican como instrumento de regulación económica. Igualmente puede serlo la decisión del Estado de intervenir directamente en el mercado a través de una empresa pública que catalice las condiciones de mercado y discipline el comportamiento de los agentes privados. Finalmente, las medidas para prohibir o reducir la entrada de nuevos agentes al mercado es una especie de regulación económica, tal como se explicará más adelante.

La regulación social está destinada a corregir fallas de mercado pero distintas a la falta de competencia, como por ejemplo son las externalidades o las asimetrías de información. La regulación social se manifiesta a través de diversos instrumentos tales como las obligaciones de entrega de información impuestas sobre los proveedores para facilitar la elección informada de los compradores; el establecimiento de estándares de producción o de desempeño para que la industria produzca y ofrezca bienes y servicios que alcancen tales parámetros; los mecanismos de aprobación previa mediante los cuales se impone condiciones de obligatorio cumplimiento previo al ingreso de agentes al mercado (títulos habilitantes) o para la introducción de bienes dentro de la oferta comercial de las empresas. La regulación social utiliza también mecanismos económicos tales como sistemas de incentivos para promover (premios o beneficios) o disuadir (castigos o cargas) la realización de ciertos comportamientos deseados o indeseados, respectivamente.

Volviendo a la regulación económica, la misma utiliza diversos instrumentos para crear reglas de comportamiento para los agentes económicos, diseñar la estructura y el funcionamiento de una determinada industria, así como controlar el poder de mercado de ciertos agentes. Una de las modalidades más intervencionistas de la regulación económica es la denominada regulación de entrada.

La regulación de entrada en sentido estricto puede definirse como las reglas que limitan

(1) Las ideas presentadas en esta sección han sido tomadas de los siguientes autores: Anthony Ogus, "Estructuras e Instituciones Regulatorias", Themis 54 (2007): 274-5. Anthony Ogus, Regulation: Legal Form and economic theory (Oxford: Hart publishing, 2004), 320-2. R. Pierce y E. Gellhorn, Regulated Industries (Minnesota: West Publishing, 1994), 244-55. Lester Salamon, The tools of government. A guide to the new governance (New York: Oxford University Press, 2002), 128-31. 


\section{Regulación de Entrada: Experiencia peruana sobre prohibiciones y restricciones para el acceso al mercado Entry regulation: Peruvian experience on prohibitions and restrictions to the market access}

la posibilidad de proveer un determinado bien o servicio a un solo agente económico o a un grupo reducido de agentes en cierto mercado, de este modo se genera un derecho exclusivo en favor de dicho agente o agentes, al impedirse por vía regulatoria que terceros adicionales realicen la misma actividad, quedando el beneficiario o beneficiarios protegidos de nueva competencia.

Según se limite total o parcialmente el ingreso de otros agentes a realizar la misma actividad económica, esta regulación puede calificarse como con efectos absolutos o relativos sobre la entrada, respectivamente.

Los sistemas de títulos habilitantes (típico instrumento de regulación social) también podrían funcionar como una especie de regulación de entrada con efectos relativos más tenues, pues limitan el ingreso de nuevos agentes hasta que el interesado dé cumplimiento a los requisitos sujetos a verificación previa por la autoridad. En tal sentido, los sistemas de títulos habilitantes solo sujetan a control previo el ingreso, pero no lo impiden una vez cumplidos los requisitos previstos. Adicionalmente, pueden tener una gran diversidad de manifestaciones, que van desde las habilitaciones más comunes (licencia municipal) hasta las más complejas (autorizaciones o concesiones sectoriales). Dada su extensión y posibles ramificaciones, en este trabajo no se abordará el estudio de mecanismos de control previo como regulación de entrada ${ }^{(2)}$.
Las razones que sustentan el uso de medidas de regulación de entrada pueden ser de diversa índole. Desde el equilibrio de monopolios naturales, hasta el control de externalidades, pasando por el control del acceso y uso de recursos escasos, el aseguramiento de obligaciones de servicio universal, y el control de riesgos de expansión del poder de mercado, ente otros. Sin perjuicio de ello, también pueden encontrarse situaciones en las que no existe una justificación apropiada para el establecimiento de medidas de regulación de entrada.

En todo caso, el sustento, forma, duración, oportunidad y alcance de las medidas de regulación de entrada determinan tanto el impacto que puede tener sobre la dinámica de los mercados, como su efectividad para el logro de los objetivos que se buscan conseguir con dichas medidas.

Por ello, es muy importante tener en cuenta los potenciales efectos negativos de la regulación de entrada, que se manifiestan en varios aspectos. Primero, puede generar restricciones severas en la dinámica de los mercados, pues crea una barrera directa a

(2) No se aborda aquí mecanismos regulatorios o reglas específicas que podrían tener un impacto indirecto sobre la entrada de nuevos agentes -retrasándola, restringiéndola o en el extremo impidiéndola indirectamente-, tales como regímenes de autorización previa con reglas desproporcionadas o irracionales, imposición de reglas vinculadas con distancias mínimas entre establecimientos, requerimiento de contar con el consentimiento previo de competidores o incumbentes para poder entrar al mercado, entre otras. Estas medidas pueden terminar disuadiendo la entrada. Tampoco se analiza mecanismos regulatorios que puedan ocasionar una entrada excesiva o ineficiente, como la desregulación prematura de un mercado o la regulación de acceso a la infraestructura del operador dominante en términos muy generosos. Diversos estudios han analizado el impacto en competencia de estas reglas, medidas o instrumentos que restringen la entrada, calificándolos en función a su potencial de restringir la competencia. Se ha planteado que los regímenes de licencia o autorización previa son también una modalidad de regulación de entrada. Al respecto, véase Lester Salamón, The tools of Government: a guide to new governance (Oxford: Oxford University Press, 2002); Shirley Svorny, Licensing and market entry regulation (2001), disponible en: http://reference.findlaw.com/lawandeconomics/5120-licensing-market-entry-regulation.pdf. Asimismo, diversos estudios han analizado el impacto en competencia de estas reglas, medidas o instrumentos que restringen la entrada, calificándolos en función a su potencial de restringir la competencia. Véase Organization for Economic Cooperation and Development, Competition Asessment Toolkit (2007), disponible en: https://www.oecd.org/competition/assessment-toolkit. htm; Tanja Goodwin y Martha Licetti, Transforming markets through competition:: new developments and recent trends in competition advocacy (2016), disponible en: http://documents.worldbank.org/curated/en/640191467990945906/Transformingmarkets-through-competition-new-developments-and-recent-trends-in-competition-advocacy. 


\section{Eduardo Quintana Sánchez y Lucia Villarán}

la competencia, ya sea totalmente (exclusividades) o cuando menos parcialmente (número reducido de agentes). Segundo, puede reducir notoriamente la posibilidad de elección de los consumidores, pues deben aceptar un solo proveedor o elegir entre menores opciones de compra. Tercero, al crear estructuras de mercado monopólicas u oligopólicas, puede hacer necesario otro tipo de intervención reguladora, por ejemplo de fijación de precios o calidades. Cuarto, puede dar lugar a que desaparezcan los incentivos a la innovación.

Teniendo ello en cuenta, la legitimidad de la regulación de entrada depende sin duda de la justificación que la sustenta, pues la necesidad de adoptarla debe ser manifiesta para considerar aceptables sus potenciales efectos negativos.

A continuación, se expone el marco legal aplicable en materia de restricciones a la entrada al mercado, en tanto normas vinculadas con la creación de monopolios legales o imposición de restricciones a la posibilidad de entrada.

\section{Marco legal aplicable sobre entrada al mercado}

El marco legal que resulta aplicable en materia de entrada al mercado se encuentra principalmente regulado en la parte del régimen económico de la Constitución Política del Perú y en la Ley Marco para el Crecimiento de la Inversión Privada, aprobada mediante Decreto Legislativo 757.

En cuanto a los principios del régimen económico constitucional, corresponde referirnos especialmente a tres artículos. En primer lugar, el artículo 58 establece que la iniciativa privada es libre y que el Estado actúa principalmente en áreas como las de servicios públicos e infraestructura, salud, o educación. Asimismo, el artículo 59 establece que el Estado garantiza la libertad de empresa, comercio e industria. Finalmente, el artículo 61 señala que ninguna ley puede autorizar ni establecer monopolios ${ }^{(3)}$.

El Decreto Legislativo 757 señala también que el Estado garantiza la libre iniciativa privada y plantea que el libre acceso a la actividad económica es base de la economía social de mercado. Asimismo, establece que la libre iniciativa privada implica el derecho de las personas a dedicarse a la actividad económica de su preferencia ${ }^{(4)}$.

Las disposiciones constitucionales y legales antes señaladas imponen límites importantes para lo que hemos definido como regulación de entrada, tanto de efectos absolutos como de efectos relativos.

De un lado, la prohibición de monopolios legales es una limitación importante para establecer regulación que tenga efectos absolutos sobre el ingreso de nuevos agentes al mercado, es decir, que lo prohíba o impida. En efecto, es claro que a través del artículo

(3) Constitución Política del Perú

Artículo 58.- La iniciativa privada es libre. Se ejerce en una economía social de mercado. Bajo este régimen, el Estado orienta el desarrollo del país y actúa principalmente en las áreas de promoción de empleo, salud, educación, seguridad, servicios públicos e infraestructura.

Artículo 59.- El Estado estimula la creación de riqueza y garantiza la libertad de trabajo y la libertad de empresa, comercio e industria. El ejercicio de estas libertades no debe ser lesivo a la moral, ni a la salud, ni a la seguridad pública. El Estado brinda oportunidades de superación a los sectores que sufren cualquier desigualdad; en tal sentido, promueve las pequeñas empresas en todas sus modalidades.

Artículo 61.- El Estado facilita y vigila la libre competencia. Combate toda práctica que la limite y el abuso de posiciones dominantes o monopólicas. Ninguna ley ni concertación puede autorizar ni establecer monopolios.

(4) Artículo 2.- El Estado garantiza la libre iniciativa privada. La Economía Social de Mercado se desarrolla sobre la base de la libre competencia y el libre acceso a la actividad económica.

Artículo 3.- Se entiende por libre iniciativa privada el derecho que tiene toda persona natural o jurídica a dedicarse a la actividad económica de su preferencia, que comprende la producción o comercialización de bienes o la prestación de servicios, en concordancia con lo establecido por la Constitución, los tratados internacionales suscritos por el Perú y las Leyes. 


\section{Regulación de Entrada: Experiencia peruana sobre prohibiciones y restricciones para el acceso al mercado Entry regulation: Peruvian experience on prohibitions and restrictions to the market access}

61 de la Constitución se dispone que las normas legales no pueden crear exclusividades o reservas de actividades en favor de un agente, al haber quedado todos sujetos a la competencia como regla fundamental de las actividades en el mercado ${ }^{(5)}$. Esta prohibición de monopolio legal no se limita a las leyes del Congreso sino que se extiende también a decisiones reglamentarias, administrativas o incluso judiciales que creen barreras de acceso al mercado que no responden a las preferencias de los consumidores ${ }^{(6)}$.

Siendo ello así, corresponde identificar cuál es el espacio que tiene la regulación con efectos absolutos sobre la entrada dentro del marco legal peruano.

Al respecto, la Octava Disposición Final y Transitoria de la Constitución establece que se pueden dictar leyes de desarrollo constitucional que establezcan mecanismos y procesos específicos para ir desmantelando progresivamente monopolios legales que pudieran existir en materia de concesiones y licencias de servicios públicos ${ }^{(7)}$. Es decir, que la Constitución admite que se mantenga ciertos monopolios legales en servicios públicos con miras a ir tratando de eliminarlos progresivamente. Lo dicho no implica una contradicción en el texto constitucional, sino una concordancia de disposiciones para el mejor logro de los objetivos de la incorporación de la competencia como regla fundamental para el funcionamiento del mercado(8).

La Octava Disposición permite modular la prohibición regulada en el artículo 61 , al admitir que ciertas actividades con características muy particulares se realicen en exclusividad, como sucede con los servicios públicos, especialmente aquellos que presentan condiciones que justifican la existencia de un solo proveedor. No obstante, esta disposición constitucional debe ser aplicada de modo excepcional cuando existan debidas razones para aplicarla (típicamente los monopolios naturales), siendo la regla general más bien

(5) Al respecto Kresalja ha señalado lo siguiente: “(...) la Doctrina peruana, en forma unánime, reconoce que por mandato del artículo 61 no pueden existir monopolios legales y, por tanto, ni las empresas públicas o privadas pueden sustraerse artificialmente de la competencia económica (...)Al adquirir la competencia una función central en el actual régimen económico constitucional, siendo rol de Estado promover o alentar a que otros produzcan antes que producir por sí mismo, la posibilidad de establecer monopolios legales pierde todo sentido y, con ello, la facultad de reservar actividades económicas en favor del Estado queda expresamente prohibida en la actual Constitución Política". Kresalja, Baldo, "La reserva de actividades económicas a favor del Estado y el régimen de los monopolios en las Constituciones de 1979 y 1993 ", IUS ET VERITAS 22 (2001): 294.

(6) Bullard plantea lo siguiente: "Prohibir un monopolio legal es imponer tanto al Poder Legislativo como al Poder Ejecutivo y en general a las instituciones públicas, una limitación a la creación sea por decisiones legislativas, reglamentarias, administrativas y hasta judiciales, de barreras de acceso al mercado que no guardan relación con las preferencias de los consumidores". Alfredo Bullard, "Artículo 61", en La Constitución comentada: análisis artículo por artículo, ed. Walter Gutierrez (Lima: Gaceta Jurídica, 2005).

(7) Constitución Política del Perú

Octava Disposición Final y Transitoria

Las disposiciones de la Constitución que lo requieran son materia de leyes de desarrollo constitucional. Tienen prioridad:

$(\ldots)$

2. Las relativas a los mecanismos y al proceso para eliminar progresivamente los monopolios legales otorgados en las concesiones y licencias de servicios públicos.

(8) Kresalja y Ochoa señalan: “(...) la permanencia de los monopolios legales preexistentes a la entrada en vigor de la Constitución de 1993, prevista en la Octava Disposición Final y Transitoria de la Constitución, y la prohibición de los monopolios legales, establecida en el artículo 61 de la Norma Suprema, que el Tribunal Constitucional, en el fundamento 24 de la sentencia pronunciada el 3 de octubre de 2003, en el Expediente No. 005-2003 AA/TC, ha precisado que no existe contradicción entre ambas disposiciones". B. Kresalja y C. Ochoa, Derecho Constitucional Económico (Lima: Pontificia Universidad Católica del Perú, 2009), 502. Ver la sentencia en: http://www.tc.gob.pe/jurisprudencia/2003/00005-2003-Al.html (Consultada el 10 de diciembre de 2016). 


\section{Eduardo Quintana Sánchez y Lucia Villarán}

la prohibición del artículo 61. Además, la aplicación de la Octava Disposición debe cumplir, en todos los casos en que sea posible, con la lógica de promover el desmantelamiento progresivo del monopolio, cuando las características de los mercados en cuestión así lo permitan.

En tal sentido, existe un espacio para utilizar excepcionalmente la regulación que prohíba o impida la entrada de competidores en los mercados de servicios públicos, pero su utilización debe encontrarse debidamente sustentada por las características especiales de los mercados y, en lo posible, debe buscarse que tales prohibiciones o impedimentos puedan levantarse progresivamente (elementos de temporalidad o de ámbito territorial de aplicación).

De otro lado, las demás disposiciones constitucionales citadas, así como las reglas previstas en la ley, garantizan el derecho de los agentes económicos a la libre iniciativa privada y a dedicarse a la actividad empresarial de su preferencia, lo que incluye sin duda el derecho a ingresar al mercado para realizar esa actividad. Es decir, existen otras normas constitucionales y legales que protegen la entrada de los agentes económicos al mercado, como parte de su libre iniciativa privada ${ }^{(9)}$.

Considerando lo anterior, si bien no existe una prohibición legal explícita como la del referido artículo 61 de la Constitución, es claro que la posibilidad de establecer regulaciones que limiten el número de agentes económicos que ingresan al mercado tampoco es irrestricta. Por ejemplo, el marco legal reconoce que en actividades o mercados de servicios públicos que se realizan mediante concesiones, las normas sectoriales pueden establecer ciertas limitaciones al régimen general de entrada al mercado(10).

Así, la regulación con efectos relativos sobre la entrada de competidores al mercado, que se manifiesta a través de limitaciones en el número de agentes habilitados o a través de sistemas de control previo, no solo necesita tener fundamento objetivo y suficiente, sino restringirse a los ámbitos permitidos por el marco legal.

Seguidamente, se presenta y comenta distintos casos de regulación de entrada, se analiza las justificaciones para su imposición $y$, en lo posible, se extraen conclusiones o recomendaciones sobre la utilización de estas herramientas regulatorias.

\section{Regulación que prohíbe o impide la entrada}

Este tipo de regulación prohíbe o impide el ingreso de competidores a un mercado, dejando solamente a una empresa en operación. Para ello, se otorga un derecho

(9) Bullard plantea que la prohibición de monopolios legales prevista en el artículo 61 de la Constitución se extiende también a supuestos como los de regulación con efectos relativos sobre la entrada: "Así, pueden caer dentro de esa prohibición de monopolio legal una ley que establece que solo podrá entregarse una actividad productiva a un número determinado de competidores, o crear reglas que exijan requisitos tan absurdos para desarrollar una actividad que solamente un número limitado de empresas pueden cumplirlas". Alfredo Bullard, "Artículo 61", en La Constitución comentada: análisis artículo por artículo, ed. Walter Gutierrez (Lima: Gaceta Jurídica, 2005).

(10) Decreto Legislativo 757

Artículo 5.- El Estado garantiza el pluralismo económico. Toda empresa tiene el derecho de organizarse bajo cualquier forma empresarial en la legislación nacional.

No puede limitarse el acceso directo o indirecto de los inversionistas o las empresas en que estos participen a actividades económicas específicas, en función a la forma empresarial que adopten. Están exceptuados de esta disposición el sistema financiero de acuerdo a la Ley que lo regula, y las excepciones que en el futuro se establezcan por Ley del Congreso. Queda derogada toda disposición legal que contravenga lo dispuesto en el presente artículo.

En los casos en que la Ley establezca que la explotación de los recursos naturales o la prestación de los servicios públicos deba realizarse mediante concesiones u otras formas de otorgamiento a los particulares, se respetará lo dispuesto en el presente Decreto Legislativo en lo que no contravenga la legislación sectorial. 


\section{Regulación de Entrada: Experiencia peruana sobre prohibiciones y restricciones para el acceso al mercado Entry regulation: Peruvian experience on prohibitions and restrictions to the market access}

exclusivo de operación de infraestructuras y/o de prestación de servicios públicos, prohibiendo o impidiendo la entrada de más empresas que pudieran estar interesadas en realizar la misma actividad.

\subsection{Justificaciones y finalidades}

Una de las principales justificaciones para este tipo de regulación de entrada es permitir el funcionamiento eficiente de monopolios naturales en mercados como los de servicios públicos.

Como se sabe, un monopolio natural se configura en aquellas actividades económicas en que se enfrenta elevados costos fijos hundidos y específicos, donde se producen economías de escala de producción tan significativas que el mercado puede ser atendido a costos más bajos por una sola empresa. En este contexto, que dos o más empresas compitan podría ocasionar efectos económicos no deseados. De un lado, las empresas tendrían que duplicar la elevada inversión en redes o infraestructura destinada a la prestación del servicio, incrementándose así el costo de provisión del mismo para los usuarios finales, pero reduciéndose el ámbito en el cual cada empresa podría beneficiarse de las economías de escala. De otro lado, cada empresa trataría de vender sus servicios a costos marginales para competir y ganar clientela, sin permitir a ninguna recuperar todos sus costos fijos con este nivel de precios.

Para evitar este resultado ineficiente producto de la competencia y permitir al menos a una empresa beneficiarse plenamente de las economías de escala, se puede optar por anular la entrada de nuevos agentes económicos en mercados que presentan características de monopolio natural. En estos supuestos, la limitación de la entrada de nuevos agentes se da a través del otorgamiento de autorizaciones o concesiones exclusivas para atender un determinado mercado. Complementariamente, se busca simular resultados de un mercado competitivo a través de la introducción de mecanismos de regulación de precios para que los beneficios de las economías de escala obtenidos por la empresa monopólica se trasladen a los consumidores $^{(11)}$.

Sin perjuicio de lo señalado, algunos autores han planteado cuestionamientos a la regulación de entrada de este tipo. Al respecto, se ha señalado que cuando las economías de escala son suficientes para justificar la limitación de entrada de otras empresas, las restricciones regulatorias serían innecesarias porque la mera existencia de estas economías de escala sería suficiente para disuadir a esas empresas de entrar al mercado. En otras palabras, sería bastante difícil que estas empresas realicen una inversión importante si ven escasas posibilidades de obtener un retorno adecuado por esa inversión ${ }^{(12)}$.

Otra posible justificación para una restricción a la entrada de nuevas empresas en determinada actividad económica se presenta cuando se busca proteger a una empresa encargada

(11) De acuerdo con Viscusi, Vernon y Harrington, la regla general es que la regulación monopolística es apropiada cuando el tamaño mínimo eficiente de la empresa (la cantidad más baja a la que se reduce al mínimo el costo medio) es igual o mayor que la demanda del mercado al precio socialmente óptimo (determinado por la cantidad en la que el costo marginal es igual al precio que los consumidores están dispuestos a pagar). Los cambios en el mercado que afectan los costos de producción o demanda modificarán la condición de monopolio natural de un mercado y requerirán reevaluar la regulación para convertirla en un mecanismo más pro-competitivo. Kip Viscusi, John Vernon y Joseph Harrington, Economic of regulation and antitrust, $4^{\mathrm{a}}$ edición (Boston: MIT Press, 2005).

(12) Al respecto, se ha indicado que existen dos circunstancias en las que una firma podría tener incentivos para entrar a un mercado que fue servido previamente por un monopolista bajo el esquema de monopolio natural: (i) cuando la firma ve el potencial de realizar "cream-skimming"; o, (ii) cuando puede usar una nueva tecnología que le permite prestar el servicio a un menor costo que el ofrecido por el monopolista. Mark Armstrong, "Regulation and inefficient entry: economic analysis and the British experience", en The anticompetitive impact of regulation, coords. Giuliano Amato y Lareal Laudati (Massachusetts: Edward Elgar, 2001), 158-60. 


\section{Eduardo Quintana Sánchez y Lucia Villarán}

de ofrecer determinadas prestaciones de interés público, de posibles competidores interesados en quitarle solamente a los clientes más rentables, es decir, cuando existe riesgo de descreme del mercado.

La situación anterior puede presentarse cuando la empresa tiene obligación de efectuar elevadas inversiones para llevar a cabo la actividad encomendada, como por ejemplo brindar el servicio a todo usuario que lo solicite dentro de una zona de concesión, dentro de un plazo determinado e independientemente de las condiciones socio-económicas de los usuarios o de su ubicación geográfica, y en la medida que se den las condiciones técnicas para hacerlo (obligaciones del tipo servicio o acceso universal).

El cumplimiento de esas obligaciones consideradas de interés público se convierte así en la prioridad de la empresa. La premisa es que al atender a todos los usuarios dentro de su zona de concesión, la empresa obtiene los recursos necesarios para financiar el cumplimiento de las referidas obligaciones. Inclusive, en algunos casos, el sistema regulatorio permite que la empresa cobre tarifas diferenciadas entre sus usuarios de modo que se genere un subsidio cruzado para financiar la atención de usuarios de menores recursos.

En tales circunstancias, no es extraño que puedan existir algunas empresas capaces y dispuestas a efectuar inversiones que les permitan ingresar al mercado para captar únicamente a los usuarios más rentables dentro de la zona de concesión del operador ya establecido, dejándolo con la obligación de atender a los usuarios menos rentables (descreme). Por ello, tampoco es extraño que se busque proteger del descreme al operador establecido a través de la regulación de entrada absoluta, para asegurar que cumpla sus obligaciones de interés público.

En algunos casos pueden combinarse las dos justificaciones antes descritas. Esto es, puede existir un monopolio natural con importantes obligaciones de inversión (costos fijos hundidos para construir o mejorar una red o infraestructura) y de atención indiscriminada de usuarios, que enfrenta el riesgo de descreme por potenciales competidores dispuestos a atender solo a los segmentos más rentables. Tales casos también constituyen una justificación para introducir regulación de entrada que busca prohibir o impedir el ingreso de esos potenciales competidores, pues mediante ella se garantiza el cumplimiento de las obligaciones de interés público impuestas al operador exclusivo.

Cabe mencionar que pueden darse variaciones en las obligaciones de interés público que se imponen al operador exclusivo y cuyo logro sustenta la elección de una regulación de entrada con efectos absolutos, tal como se mostrará en los siguientes ejemplos de industrias de redes y servicios públicos en el Perú.

\subsection{Prohibiciones de entrada en energía, telecomunicaciones e infraestructura de transporte}

4.2.1. Servicios de distribución de electricidad y gas

En primer lugar, puede mencionarse las concesiones para la actividad de distribución de energía eléctrica. En este caso, la Ley de Concesiones Eléctricas, Decreto Ley 25844, otorga a cada distribuidora la exclusividad en el suministro de energía eléctrica a todos los usuarios ubicados dentro de su zona de concesión, cuyos consumos califiquen como de Servicio Público de Electricidad, durante todo el plazo de la concesión. Esto significa que la actividad de distribución con esas características solo puede ser desarrollada por un titular con carácter exclusivo dentro de la zona de concesión respectiva ${ }^{(13)}$. Sin perjuicio de ello, la otra cara de la moneda de tal exclusividad es que la distribuidora se encuentra obligada a brindar el servicio

(13) Decreto Ley 25844

Artículo 30.- La actividad de distribución de Servicio Público de Electricidad en una zona determinada, solo puede ser desarrollada por un solo titular con carácter exclusivo. La concesión de distribución no puede ser reducida sin autorización del Ministerio de Energía y Minas (...) 


\section{Regulación de Entrada: Experiencia peruana sobre prohibiciones y restricciones para el acceso al mercado Entry regulation: Peruvian experience on prohibitions and restrictions to the market access}

de suministro de electricidad, dentro de un lapso temporal máximo de 1 año, a cualquiera que se lo requiera dentro de su zona de concesión o incluso a quien llegue a ella por sus propios medios $^{(14)}$.

En segundo lugar, puede comentarse sobre las concesiones de distribución de gas natural por redes de ductos. En estos casos, los Contratos BOOT de las dos principales distribuidoras existentes a la fecha (Cálidda y Contugas) señalan expresamente que el servicio de distribución tiene carácter exclusivo en toda el área de la concesión durante el plazo del respectivo contrato ${ }^{(15)}$. Como correlato de la referida exclusividad, el concesionario se encuentra obligado a brindar el servicio de distribución a quien lo solicite dentro de su área de concesión, en un plazo máximo de 45 días si cuenta con la infraestructura necesaria en la zona, o de 12 meses si no cuenta con ella(16).

Las concesiones de distribución de electricidad y de gas natural pueden caracterizarse como un monopolio natural, y en ambos casos se ha impuesto la obligación de atender toda solicitud de suministro en la respectiva zona de concesión en un plazo máximo de 12 meses. Paralelamente, en ambos casos se ha establecido también una exclusividad en la prestación del servicio, lo que implica necesariamente la prohibición de que otros agentes ingresen a competir con los concesionarios en el suministro de electricidad y gas natural en el área geográfica correspondiente.

4.2.2. Servicios de telefonía fija y de larga distancia

En otros casos se ha establecido regulación con efectos absolutos sobre la entrada, pero solo con carácter temporal. El otorgamiento de un monopolio temporal al inicio de la privatización de los activos de la Compañía Peruana de Teléfonos (CPT) y Entel Perú (Entel) es un caso muy interesante al respecto $^{(17)}$.

(14) Decreto Ley 25844

Artículo 34.- Los Distribuidores están obligados a:

a) Suministrar electricidad a quien lo solicite dentro de su zona de concesión o a aquellos que lleguen a dicha zona con sus propias líneas, en un plazo no mayor de un (1) año y que tengan carácter de Servicio Público de Electricidad.

(15) Contrato BOOT de Concesión para el diseño, suministro de bienes y servicios y construcción del Sistema de Distribución de Gas Natural por Red de Ductos en el Departamento de Lima y la Provincia Constitucional del Callao.

3.1. Exclusividad del servicio y desarrollo del Sistema de Distribución:

El servicio de Distribución tendrá el carácter de exclusivo en toda el Área de la Concesión durante el Plazo del Contrato, sin perjuicio de lo dispuesto en la cláusula 3.1.3.

$(\ldots)$

3.1.3. Luego de un plazo de 12 años contados a partir de la Puesta en Operación Comercial, el Servicio de Distribución estará sujeto a lo dispuesto en los artículos $7^{\circ}, 23^{\circ}$ y $37^{\circ}$ inciso "f" del Reglamento.

Contrato BOOT de Concesión para el diseño, suministro de bienes y servicios y construcción del Sistema de Distribución de Gas Natural por Red de Ductos en el Departamento de Ica y la explotación de los bienes de la concesión.

2.3. Exclusividad del servicio:

El servicio de Distribución será prestado en exclusividad por la Sociedad Concesionario en toda el Área de la Concesión durante la vigencia del Contrato. Luego de un plazo de ocho (8) años contados a partir de la Puesta en Operación Comercial, el Servicio de Distribución se sujetará a lo dispuesto en los artículos 7, 23 y 37 inciso "f" del Reglamento.

(16) Texto Único Ordenado del Reglamento de Distribución de Gas Natural por Red de Ductos, Decreto Supremo No. 040-2008-EM Artículo 42.- El Concesionario está obligado a:

(...)

b) Dar servicio a quien lo solicite dentro del Área de Concesión dentro de un plazo no mayor de cuarenta y cinco (45) días en caso existiera la infraestructura necesaria en la zona, o de doce (12) meses si no la hubiera, siempre que el Suministro se considere técnica y económicamente viable de acuerdo al artículo 63 y al Procedimiento de Viabilidad. Los plazos se computarán a partir de la suscripción del correspondiente contrato.

(17) La siguiente descripción reproduce lo comentado sobre este asunto por uno de los autores en: Eduardo Quintana, “¿Es la política de competencia ‘supletoria' de la regulación de telecomunicaciones?", IUS ET VERITAS 27 (2003). 


\section{Eduardo Quintana Sánchez y Lucia Villarán}

En efecto, al decidirse la transferencia de CPT y Entel al sector privado, se consideró importante vender la participación del Estado en ambas empresas como un solo paquete y otorgar el control de las mismas al nuevo operador, incluyendo la exclusividad en la prestación de los servicios de telefonía fija local y de larga distancia por un período determinado. Para ejecutar este plan, en enero de 1994 se estableció el régimen de desmonopolización progresiva para los servicios de telefonía fija local y portador de larga distancia, según el cual dichos servicios quedaron sujetos a una etapa máxima de 5 años de concurrencia limitada o exclusividad, para adecuarse a la competencia. Los demás servicios públicos de telecomunicaciones que brindaban dichas empresas se dejaron fuera del alcance de este régimen ${ }^{(18)}$. Esto significaba que la prestación de servicios de telefonía fija y de larga distancia se mantendría bajo monopolio temporal hasta por 5 años.

En febrero de 1994 se llevó a cabo el proceso de subasta de acciones de CPT y Entel. El nuevo operador inició sus actividades en junio de 1994 (OSIPTEL 1999, 19-20). En función de ello, el monopolio temporal se podía mantener hasta fines de junio de 1999. Este monopolio temporal fue otorgado a cambio de que el operador ganador cumpliera diversas metas de expansión, de modernización y de calidad de los servicios que le fueron otorgados en concesión ${ }^{(19)}$. Todas las metas se cumplieron entre 1997 (OSIPTEL 1998, 47-50) y el primer semestre de 1998 (OSIPTEL 1999, 33-34).

Adicionalmente, antes de la privatización se utilizaba un sistema de notorios subsidios cruzados (la tarifa de telefonía fija no cubría los costos y era financiada a través de la tarifa de larga distancia que tenía un fuerte sobre precio). Por ello, una condición también impuesta al operador ganador fue que en ese mismo período llevara a cabo el denominado rebalanceo tarifario para que los precios de ambos servicios pasaran a responder a sus costos efectivos de provisión, asegurándose de este modo que el abandono del sistema de subsidios cruzados se dejara gradualmente y no de forma inmediata para evitar el malestar en el público usuario de los servicios de telefonía fija.

Téngase en cuenta que si bien en esa época podía considerarse que el servicio de telefonía fija tenía características de monopolio natural, era claro que el servicio de larga distancia no tenía esas características y podía ser rápidamente competitivo. Siendo ello así, podría llamar la atención que se haya decidido otorgar un monopolio temporal (lo que implica una prohibición de entrada temporal) no solo para el servicio de telefonía fija sino también para el de larga distancia. Sin embargo, esta decisión cobra sentido en el contexto de la necesidad de un rebalanceo tarifario gradual. En ausencia del monopolio temporal sobre ambos servicios, el ganador habría reducido inmediatamente la tarifa de los servicios de larga distancia para hacer frente a posibles competidores que habrian ingresado de inmediato a este segmento del mercado. Con ello se habría quedado también inmediatamente sin recursos para financiar la tarifa por debajo de costos que se cobraba por los servicios de telefonía fija.

En este caso, la prohibición temporal de entrada en segmentos sin características de monopolio natural sino claramente competitivos (larga distancia), se justificaba por la obligación de interés público impuesta sobre la empresa ganadora para que efectúe el rebalanceo tarifario de manera gradual.

\subsubsection{Servicios de infraestructura aeroportuaria}

De otro lado, la regulación de entrada puede tener alcances limitados no solo en lo temporal

(18) Ley de Desmonopolización Progresiva de los Servicios Públicos de Telecomunicaciones de Telefonía Fija Local y de Servicios de Portadores de Larga Distancia, Ley 26285.

(19) Tales metas incluyeron los siguientes rubros: crecimiento de líneas instaladas, incremento del número de teléfonos públicos, reducción del tiempo de espera para la instalación de nuevas líneas, sustitución de centrales manuales por digitales, conexión de aproximadamente 1,500 centros poblados a la red y mejoras en la calidad que se medirían en función de indicadores como la tasa de incidencia de fallas o el número de llamadas completadas. 


\section{Regulación de Entrada: Experiencia peruana sobre prohibiciones y restricciones para el acceso al mercado Entry regulation: Peruvian experience on prohibitions and restrictions to the market access}

sino también en lo geográfico. Veamos el caso del proceso de promoción de la inversión privada en el Aeropuerto Internacional Jorge Chávez.

Como se sabe, los requerimientos exigidos al ganador de este proceso involucraban no solo la modernización de las instalaciones y la mejora en los servicios aeroportuarios ofrecidos previamente por la empresa estatal Corpac, sino también la construcción y operación de un nuevo terminal sobre los terrenos que fueran entregados por el Estado.

A la par de estas y otras obligaciones asociadas con la operación del aeropuerto, el Estado ofreció al ganador del proceso como garantía para que invirtiese y operase confiado en obtener un retorno adecuado por sus inversiones, que durante los primeros 20 años de la concesión no otorgaría a ningún tercero, ni tampoco al propio Estado, una concesión, autorización o licencia para operar cualquier nuevo aeropuerto de uso público que brinde servicios comerciales, dentro de un radio de 150 kilómetros de la ubicación del Aeropuerto Internacional Jorge Chávez ${ }^{(20)}$.

Como se observa, en este caso, vía el Contrato de Concesión, se aseguró al Concesionario un monopolio geográfico temporal en la prestación de servicios aeroportuarios de carácter comercial, esto es, se le aseguró que durante 20 años sería el único operador de servicios aeroportuarios comerciales en el ámbito correspondiente a los 150 kilómetros equidistantes al Aeropuerto Internacional Jorge Chávez. Así, el propio Estado se auto impidió otorgar concesión, licencia o autorización alguna que pudiera contradecir la exclusividad otorgada al concesionario establecido.

Sin perjuicio de lo anterior, por los términos del monopolio geográfico temporal otorgado, queda sobre entendido que si la demanda por servicios aeroportuarios comerciales de la población de Lima y Callao creciera de modo sustancial, como para hacer necesaria la construcción y operación de otro aeropuerto, el mismo podría instalarse fuera del ámbito geográfico protegido.

Los casos previos explican cómo funciona la regulación con efectos absolutos sobre la entrada, prohibiendo o impidiendo el ingreso de nuevos competidores a través de derechos exclusivos de explotación de infraestructuras y prestación de servicios públicos. Estos casos muestran que es usual el establecimiento de este tipo de regulación en industrias de redes con características de monopolio natural, en las cuales existen obligaciones de realizar importantes inversiones en infraestructuras con carácter de costo hundido.

También indican que los operadores, en cuyo favor se impone la regulación de entrada, asumen obligaciones de atención a todos los

(20) Contrato de Concesión del Aeropuerto Internacional Jorge Chávez (2000) suscrito por Lima Airport Partners.

Clausula 2.5. Garantía del Estado.

El Concedente realizará todas las gestiones y coordinaciones que fueren pertinentes para que en virtud de lo dispuesto en el artículo 4 de la Ley 26885, el Poder Ejecutivo expida el Decreto Supremo al que se refiere el artículo 2 del Decreto Ley 25570, modificado por el artículo 6 de la Ley 26438, por el cual se otorgará la garantía del Estado en respaldo de las obligaciones, declaraciones y garantías del Concedente establecidas en el presente Contrato. Asimismo el Concedente durante los primeros veinte (20) años de Vigencia de la Concesión se obliga a no otorgar concesión, autorización o licencia alguna para operar, u operar por sí mismo cualquier nuevo aeropuerto nacional e internacional de uso público que brinde servicios a líneas aéreas comerciales, destinado en forma habitual a la llegada, salida y movimiento de aeronaves, pasajeros y carga en un radio de $150 \mathrm{Km}$. de la ubicación del Aeropuerto. El Concedente no se encuentra impedido de otorgar concesión, autorización o licencia para operar, u operar por sí mismo cualquier aeropuerto destinado a la salida, llegada, y movimiento de aeronaves cuyo número de asientos sea menor o igual a nueve (9) y cuyo peso máximo de despegue sea menor o igual a cinco mil setecientos $(5,700)$ kilogramos. En el supuesto de autorizar la salida, llegada y/o movimiento de cualquier otro tipo de aeronave de mayor peso o de mayor número de asientos deberá obtenerse, previamente, la aprobación del Concesionario (el resaltado en añadido). El texto actualizado puede encontrarse en el siguiente enlace: https://www.mtc.gob.pe/transportes/concesiones/documentos/TUO-LAP.pdf 


\section{Eduardo Quintana Sánchez y Lucia Villarán}

usuarios dentro de la zona de concesión, y que sus actividades pueden ser proclives al descreme del mercado. Finalmente, los casos planteados muestran que la regulación de entrada puede modularse en términos geográficos y temporales, con el fin de asegurar a los concesionarios períodos adecuados para la maduración de sus inversiones y para el cumplimiento de mandatos específicos y particulares de cada industria (como en el caso del rebalanceo tarifario en telefonía fija y de larga distancia); pero también con la lógica de desmantelar progresivamente monopolios allí donde las características del mercado lo permitan.

Sin embargo, el establecimiento de regulación con efectos absolutos sobre la entrada no siempre encuentra un sustento adecuado en todas las industrias, tal como se muestra en el siguiente acápite.

\subsection{Prohibición de entrada sin sustento en el caso de revisiones técnicas vehiculares}

Mediante Ordenanza 506, la Municipalidad Metropolitana de Lima (MML) estableció que todos los vehículos automotores que circularan en la jurisdicción de la Provincia de Lima y que tuvieran 2 años de antigüedad (particulares) o 1 año de antigüedad (servicio público) debían pasar la revisión técnica vehicular ${ }^{(21)}$.

Posteriormente, vía Resolución de Comité Especial de Promoción de la Inversión Privada No. 01-2004-MML/ CEPRI LIMA, se adjudicó la concesión para la ejecución de la infraestructura de plantas de revisiones técnicas y la explotación del servicio de revisiones técnicas vehiculares para Lima Metropolitana al Consorcio Ivesur - Lidercon. En el respectivo contrato de concesión, se otorgó al referido consorcio la exclusividad en la prestación del servicio en Lima Metropolitana.

Más adelante, también en el año 2004, la MML estableció mediante la Ordenanza 694 que solo las plantas de revisiones técnicas debidamente autorizadas por la Municipalidad podrían prestar el servicio de revisión técnica vehicular. Asimismo, dispuso que el otorgamiento de concesiones para la prestación del servicio de revisión técnica vehicular se realizaría a través de un concurso público para la elección del postor ganador según las normas pertinentes a nivel local|22).

La exclusividad otorgada por la MML al Consorcio Ivesur-Lidercon fue analizada de oficio por la Comisión de Eliminación de Barreras Burocráticas del INDECOPI y en el año 2008 fue declarada como una barrera burocrática ilegal, que contravenía lo dispuesto por la Constitución Política del Perú y el Decreto Legislativo $757^{(23)}$.

En particular, la referida Comisión consideró que la Ordenanza 694 había avalado la creación por norma legal de una exclusividad otorgada vía contrato de concesión para la realización de una actividad económica (revisiones técnicas vehiculares) en favor de una empresa (Ivesur-Lidercon). En particular,

(21) Ordenanza 506 de la Municipalidad Metropolitana de Lima (publicada el 9 de junio de 2003).

(22) Ordenanza 694 de la Municipalidad Metropolitana de Lima (publicada el 19 de setiembre de 2004). Regula el Procedimiento Técnico y Administrativo del Sistema de Revisiones Técnicas Vehiculares y el funcionamiento de la plantas de revisiones técnicas en Lima Metropolitana

Artículo 24.- Obligatoriedad de la autorización

Solo las Plantas de Revisiones Técnicas debidamente autorizadas por la Municipalidad Metropolitana de Lima podrán prestar el servicio de Revisión Técnica Vehicular.

Primera Disposición Complementaria y Transitoria

El otorgamiento de concesiones para la prestación del Servicio de Revisiones Técnicas Vehiculares será llevado a cabo mediante un procedimiento de selección, con precalificación de los postores, conforme a lo previsto en sus Bases; y por el Decreto de Alcaldía No. 166-2002-MML, Texto Único Ordenado del Reglamento de las Inversiones Privadas en obras públicas de infraestructura y de servicios públicos locales para la provincia de Lima. La ejecución del contrato de concesión también se regulará por lo previsto en el citado Texto Único Ordenado.

(23) Resolución No. 0013-2008/CAM-INDECOPI del 24 de enero de 2008 (Expediente No. 000101-2007/CAM). 


\author{
Regulación de Entrada: Experiencia peruana sobre prohibiciones y \\ restricciones para el acceso al mercado \\ Entry regulation: Peruvian experience on prohibitions and \\ restrictions to the market access
}

la MML había establecido que el referido Consorcio sería el único habilitado para brindar con carácter oficial el servicio de revisiones técnicas vehiculares en la ciudad de Lima, por un plazo de 16 años, constituyéndose así un monopolio legal sin sustento.

Entre los argumentos planteados por la MML en su defensa, se encuentra que la actividad de revisiones técnicas vehiculares no era una actividad económica sujeta a comercio sino una actividad realizada en ejercicio de funciones de supervisión que según la decisión de la autoridad competente (es decir, la $\mathrm{MML}$ ) podía ser realizada directamente por ella o, vía delegación, por un tercero designado para tales efectos.

Al respecto, la Comisión de Eliminación de Barreras Burocráticas del INDECOPI indicó que si bien la MML tenía facultades legales para verificar y controlar el funcionamiento de vehículos automotores así como para establecer la obligación legal de los titulares de vehículos de someterse a esta revisión técnica, esa función se había implementado utilizando un mecanismo que creaba un monopolio legal para la prestación del servicio de revisiones técnicas de carácter oficial para Lima Metropolitana, lo que se encuentra prohibido por la Constitución y la ley. Asimismo, la Comisión señaló que si bien la función municipal de fiscalizar el parque automotor no es una actividad económica, el medio para implementar esa función (el servicio de revisiones técnicas oficiales) sí lo es y, por lo tanto, su otorgamiento en condiciones de exclusividad era susceptible de generar distorsiones en las condiciones de competencia en el mercado ${ }^{(24)}$.

La Comisión sostuvo que esta medida impedía que otros agentes económicos pudieran dedicarse a brindar servicios de revisión técnica vehicular que tuvieran carácter oficial para efectos de la MML, lo que ocasionaba que los titulares de los vehículos automotores se vieran obligados a contratar dicho servicio con una sola empresa, sin que existiese una justificación para ello.

Aun cuando la MML mencionó que la actividad en cuestión tendría características de monopolio natural que justificaban la exclusividad otorgada, este aspecto nunca llegó a ser acreditado. El hecho de que luego de la remoción de la exclusividad hayan ingresado al mercado otras empresas que prestan el servicio de revisiones técnicas y que actualmente exista competencia en la prestación de este servicio, pone de manifiesto que la exclusividad impuesta restringía arbitrariamente la entrada de nuevos competidores en un mercado potencialmente competitivo, con el consecuente perjuicio a los consumidores, que se veían forzados a contratar el servicio en condiciones monopólicas.

Este caso permite concluir que en ausencia de una justificación clara para imponer regulación con efectos absolutos sobre la entrada, el impacto negativo de este tipo de medidas en las condiciones de competencia y el bienestar de los consumidores o usuarios puede ser significativo, siendo aconsejable abstenerse de establecerla.

\section{Regulación que limita la entrada sin prohibirla o impedirla}

Este tipo de regulación reduce el número de agentes que pueden actuar en el mercado (no impide su ingreso). Para ello se utiliza mecanismos que controlan y definen el número de agentes habilitados para realizar determinada actividad (por ejemplo, concursos públicos que producen competencia por el mercado) o sistemas que exigen el cumplimiento de requisitos antes de ingresar al mercado (sistemas de títulos habilitantes con control previo del cumplimiento de requisitos).

El grado de intervención de la autoridad es mayor en los mecanismos que limitan el número de agentes autorizados, que en

(24) Al respecto, la Comisión indicó lo siguiente: "Actividad económica es toda acción en la que se producen o intercambian bienes y servicios, con la posibilidad de obtener ganancias. En este caso, cuando la MML decidió trasladar la operación del sistema de revisiones técnicas al sector privado creó una actividad económica". 


\section{Eduardo Quintana Sánchez y Lucia Villarán}

aquellos que permiten el ingreso de todos los interesados que cumplan los requisitos previos. Como ya se adelantó, en este trabajo no se abordará los mecanismos de regulación de entrada basada en sistemas de títulos habilitantes, dada la infinidad de manifestaciones que la misma puede adquirir.

\subsection{Justificaciones y finalidades}

La justificación comúnmente asociada con este tipo de regulación de entrada tiene que ver con la administración de recursos calificados como escasos. El carácter escaso de ciertos bienes (por ejemplo, recursos naturales) exige que se limite el número de sujetos que pueden hacer uso de ellos o explotarlos económicamente, pues de otro modo se haría imposible su aprovechamiento racional y eficiente.

Al respecto, la escasez es una restricción en la oferta de bienes que no son fácilmente sustituibles, y puede deberse a múltiples razones. Frente a ella, una opción sería no intervenir regulatoriamente y dejar que se genere alguna solución a través de mecanismos de mercado; por ejemplo, que ante la menor oferta se incremente el precio y el bien se encuentre disponible solamente para aquellos en capacidad de pagar ese mayor precio. Otra opción puede ser más bien intervenir para definir a quien corresponderá la titularidad de derechos de uso de ese bien, para lograr una utilización más racional y segura. Esta intervención reguladora puede ocurrir, por ejemplo, cuando las características de los bienes impiden su utilización simultánea o concurrente por diversos sujetos que lo requieren, como consecuencia de limitaciones de espacio o condiciones técnicas (Ogus 2004, 42-43).

Así, en ausencia de disposiciones que reduzcan el número de agentes económicos habilitados para explotar esos bienes, podría generarse un uso o consumo desmesurado, poniéndose en riesgo su sostenibilidad. Siendo inaceptable el uso sin control y desorganizado de esos bienes, la regulación de entrada permite administrar la escasez con resultados eficientes.

Siendo que también se verifican potenciales problemas de uso inseguro de esos bienes escasos, también puede plantearse que este tipo de regulación de entrada cumple a su vez una lógica de control de externalidades, para que su utilización sea de forma razonable y bajo condiciones que aseguren su sostenibilidad en el tiempo, como ocurre con los recursos naturales.
Los siguientes ejemplos son muestra de regulaciones que no impiden la entrada al mercado pero que sí la restringen ya sea por el número de agentes que pueden participar en él o, en todo caso, imponiendo restricciones a agentes que ya operan en el mercado para que amplíen su participación en el mismo a través del control de mayores proporciones de un recurso escaso o de ciertas infraestructuras.

En dichos ejemplos, se puede identificar la lógica de uso eficiente de recursos escasos así como de uso racional de los mismos para evitar externalidades. De otro lado, también se identifica que dichas medidas reguladoras pueden tener el objeto de proteger la competencia y facilitar que funcione el mercado.

\subsection{Restricciones a la entrada en telecomunicaciones, radio y televisión, e infraestructura de transporte}

5.2.1. Servicios de telecomunicaciones y espectro radioeléctrico

La regulación en materia de asignación del espectro radioeléctrico para la prestación de servicios de telecomunicaciones contiene un diseño de regulación con efectos relativos sobre la entrada, pues si bien no otorga una exclusividad en la prestación de los referidos servicios, sí determina el número de operadores que pueden participar en el mercado.

Los servicios de telecomunicaciones que requieren utilizar espectro radioeléctrico son diversos. Entre ellos, se puede mencionar la telefonía móvil y la telefonía fija inalámbrica, el servicio de televisión satelital, el servicio de Internet móvil, y los servicios móviles por satélite. Son los servicios de telefonía e Internet móvil los que han dado lugar al establecimiento de regulación con efectos relativos sobre la entrada en función a la disponibilidad de espectro radioeléctrico. 


\section{Regulación de Entrada: Experiencia peruana sobre prohibiciones y restricciones para el acceso al mercado Entry regulation: Peruvian experience on prohibitions and restrictions to the market access}

El espectro radioeléctrico es un medio intangible que permite trasladar señales de comunicaciones (voz, imágenes y datos) sin necesidad de utilizar una red de cables. Si no se distribuye adecuadamente su uso, las señales cursadas podrían interferirse entre sí, degradando la calidad de la comunicación o haciéndola imposible. Adicionalmente, el espectro es un medio de transporte con capacidad limitada. Por estas características, en el caso de algunos servicios -particularmente los de telefonía e Internet móvil- pueden existir varias empresas interesadas en prestarlos, pero esto no es viable debido al tamaño limitado del espectro radioeléctrico disponible y a los riesgos de interferencia entre los servicios que serían ofrecidos por todas esas empresas.

El marco legal de telecomunicaciones establece que el espectro radioeléctrico es el medio por el cual pueden propagarse las ondas radioeléctricas sin guía artificial; está calificado como un recurso natural de carácter limitado; y el Ministerio de Transportes y Comunicaciones (en adelante "MTC") se encarga de la administración, atribución, asignación y control del espectro de frecuencias radioeléctricas ${ }^{(25)}$. Se establece que los servicios públicos de telecomunicaciones que emplean estaciones radioeléctricas tienen bandas de frecuencias específicas atribuidas en el Plan Nacional de Asignación de Frecuencias (en adelante "PNAF")(26). A través del PNAF se atribuye las distintas frecuencias del espectro a la prestación de determinados servicios, clasificándose así los usos admisibles del espectro radioeléctrico. La atribución tiene distintas finalidades: (i) asegurar la operatividad de los servicios; (ii) minimizar la probabilidad de interferencias perjudiciales entre ellos o entre operadores del mismo servicio; y, (iii) permitir la coexistencia de servicios dentro de una misma banda de frecuencias, cuando sea el caso(27).

En otras palabras, el Estado atribuye determinada sección del espectro (banda) para la prestación de un tipo de servicio, y luego asigna porciones de dicha banda (frecuencias) a los operadores de servicios interesados. De conformidad con la regulación de la materia, la asignación de espectro se otorga ya sea a pedido de parte o mediante concurso público de ofertas ${ }^{(28)}$, siendo este último obligatorio en cualquiera de los siguientes escenarios:

- En una determinada localidad o área de servicio, exista restricción en la disponibilidad de frecuencias o banda de frecuencias disponible, para la prestación de un determinado servicio público de telecomunicaciones.

- Se señale en el PNAF.

- Se restrinja el número de concesionarios de un determinado servicio público debido a restricciones técnicas basadas en recursos escasos ${ }^{(29)}$.

(25) TUO del Reglamento General de la Ley de Telecomunicaciones, Decreto Supremo No. 020-2007-MTC.

Artículo 199.- Definición. Espectro radioeléctrico es el medio por el cual pueden propagarse las ondas radioeléctricas sin guía artificial. Constituye un recurso natural limitado que forma parte del patrimonio de la nación. Corresponde al Ministerio la administración, la atribución, la asignación y el control del espectro de frecuencias radioeléctricas y, en general, cuanto concierne al espectro radioeléctrico.

(26) Decreto Supremo No. 020-2007-MTC

Artículo 209.- Bandas para servicios públicos

Los servicios públicos de telecomunicaciones que emplean estaciones radioeléctricas tienen bandas de frecuencias específicas atribuidas en el PNAF.

(27) EI PNAF ha sido aprobado a través de la Resolución Ministerial No. 187-2005-MTC-03.

(28) Decreto Supremo No. 02-2007-MTC

Artículo 121.- Régimen de concesión. Los servicios portadores, finales y de difusión de carácter público, se prestan bajo el régimen de concesión, la cual se otorga previo cumplimiento de los requisitos y trámites que establecen la Ley y el Reglamento y se perfecciona por contrato escrito aprobado por el Titular del Ministerio.

Artículo 122.- Mecanismos para el otorgamiento de concesión y asignación de espectro radioeléctrico. Las concesiones, así como la asignación de espectro que corresponda, se otorgarán a solicitud de parte o mediante concurso público de ofertas.

(29) Decreto Supremo No. 020-2007-MTC 


\section{Eduardo Quintana Sánchez y Lucia Villarán}

Siendo que la asignación de espectro se otorga a través de un concurso, solo uno de los postores logra obtener el derecho de uso, quedando excluidos los demás. Con ello, el sistema regulatorio de acceso al espectro radioeléctrico determina el número de agentes que operan en el mercado.

Esto se ha hecho más evidente en el caso de la asignación de espectro para brindar servicios públicos de telecomunicaciones en Lima y Callao, pues se ha dispuesto que la asignación se realice siempre por concurso público de ofertas. También se ha señalado que debe recurrirse al concurso en caso de restricciones a la disponibilidad de frecuencias o banda de frecuencias fuera de Lima y Callao ${ }^{(30)}$.

En el caso particular de los servicios de telefonía e Internet móvil, siempre se ha utilizado concursos administrados por la Agencia de Promoción de la Inversión - PROINVERSIÓN para la asignación del espectro correspondiente, lo que ha determinado un número reducido de operadores de tales servicios, el mismo que ha variado regularmente entre 3 y 4 operadores en las últimas dos décadas.

\subsubsection{Radio y televisión, y frecuencias} disponibles

Una situación similar ocurre con la regulación aplicable a las licencias para la prestación de los servicios de radio y televisión de señal abierta (no pagas). Ambos servicios también utilizan espectro radioeléctrico para propagar sus señales y el MTC es el encargado de otorgar las autorizaciones respectivas, que incluyen la asignación de las frecuencias de espectro radioeléctrico(31). Para tales efectos, en el PNAF se atribuyen las bandas de frecuencias para radio y televisión correspondientes a las distintas localidades del territorio nacional, y se determinan las frecuencias técnicamente disponibles en cada localidad (es decir, las frecuencias que pueden ser asignadas a interesados) ${ }^{(32)}$.

Artículo 123.- Concurso público. El otorgamiento de la concesión, así como las asignaciones de espectro que correspondan, se efectuarán obligatoriamente por concurso público de ofertas cuando:

1. En una determinada localidad o área de servicio, exista restricción en la disponibilidad de frecuencias o banda de frecuencias disponible, para la prestación de un determinado servicio público de telecomunicaciones.

2. Se señale en el PNAF.

3. Se restrinja el número de concesionarios de un determinado servicio público al amparo del artículo 70 de la Ley debido a restricciones técnicas basadas en recursos escasos.

TUO de la Ley de Telecomunicaciones, Decreto Supremo No. 013-93-TCC

Artículo 70.- Por Decreto Supremo se podrá restringir el número de concesionarios de un determinado servicio. Las restricciones adoptadas pueden incorporarse en los contratos de concesión. En los casos antes referidos será obligatorio el otorgamiento de las concesiones por el mecanismo de concurso público.

(30) Decreto Supremo No. 020-2007-MTC

Artículo 203.- La asignación del espectro radioeléctrico en las bandas identificadas para la prestación de servicios públicos de telecomunicaciones y atribuidas a título primario, se realizará mediante concurso en el Provincia de Lima y en la Provincia Constitucional del Callao. Para tal efecto, el Ministerio emitirá los dispositivos correspondientes. Esta disposición no aplica a las asignaciones ya efectuadas en las referidas bandas, durante la vigencia de sus contratos ni para los radioenlaces digitales para la prestación de servicios públicos de telecomunicaciones en las bandas atribuidas como tales en el PNAF. El Plan Nacional de Atribución de Frecuencias (PNAF) se adecuará a lo dispuesto en el presente artículo. En caso de restricciones a la disponibilidad de frecuencias o banda de frecuencias fuera de la Provincia de Lima y en la Provincia Constitucional del Callao, se seguirá lo establecido en el artículo 123.

(31) Ley de Radio y Televisión, Ley 28278

Artículo 11.- Del espectro radioeléctrico

El espectro radioeléctrico es un recurso natural de dimensiones limitadas que forma parte del patrimonio de la Nación. Su utilización y otorgamiento para la prestación del servicio de radiodifusión, se efectúa en las condiciones señaladas en la presente Ley y las normas internacionales de la Unión Internacional de Telecomunicaciones.

Corresponde al Ministerio la administración, la atribución, la asignación, el control y en general cuanto concierne a la gestión del espectro atribuido a dicho servicio, así como la representación del Estado ante la Unión Internacional de Telecomunicaciones.

(32) Reglamento de la Ley de Radio y Televisión, Decreto Supremo No. 005-2005-MTC 


\section{Regulación de Entrada: Experiencia peruana sobre prohibiciones y restricciones para el acceso al mercado Entry regulation: Peruvian experience on prohibitions and restrictions to the market access}

El régimen de acceso a las autorizaciones y espectro es también a solicitud de parte, o por concurso público en caso el espectro disponible resulte insuficiente en el ámbito geográfico respectivo, es decir, cuando la cantidad de frecuencias o canales disponibles en una misma banda y localidad es menor al número de solicitudes presentadas. Para tales efectos, se ha previsto que la autoridad conduzca dos concursos anuales ${ }^{(33)}$.

Como se observa, el régimen de autorizaciones para brindar servicios de radio y televisión también implica una regulación de entrada que limita el número de agentes que pueden operar en el mercado, cuando las frecuencias de espectro disponibles para cada localidad son insuficientes para cubrir las solicitudes de todos los interesados. Al haberse predefinido el número de frecuencias técnicamente disponibles en cada localidad y al utilizarse luego el sistema de concurso público, sucederá que solo algunos logren obtener el título habilitante y otros no.
5.2.3. Facilidades esenciales de infraestructuras de transporte

Otro régimen que puede tener el efecto de limitar la entrada de operadores al mercado se presenta en las normas sobre acceso a facilidades esenciales de infraestructuras de transporte de uso público (aeropuertos, ferrocarriles y puertos).

Las normas de la materia establecen que los Usuarios Intermedios (es decir, las empresas que utilizan dicha infraestructura para brindar sus servicios, como aerolíneas, empresas navieras, etcétera) ${ }^{(34)}$ tienen derecho a acceder a ciertas prestaciones de los titulares de dicha infraestructura, que son calificadas como Facilidades Esenciales por la regulación(35).

Artículo 7.- Asignación de frecuencias

Los servicios de radiodifusión se prestan en las bandas atribuidas en el PNAF. Toda asignación de frecuencias para el servicio de radiodifusión se efectúa en base al Plan Nacional de Atribución de Frecuencias, el cual comprende los Planes de Canalización y Asignación de Frecuencias correspondientes a cada localidad y banda de frecuencias atribuida al servicio de radiodifusión, y determina las frecuencias técnicamente disponibles.

(33) Reglamento de la Ley de Radio y Televisión, Decreto Supremo No. 005-2005-MTC

Artículo 19.- Autorización para prestar el servicio de radiodifusión

Los servicios de radiodifusión se prestan previo otorgamiento de la autorización respectiva. La autorización es concedida mediante Resolución del Viceministro de Comunicaciones, una vez cumplidos los requisitos y procedimientos establecidos en la Ley, el Reglamento y demás normas aplicables, siempre que no exista impedimento o prohibición para su otorgamiento, o que se configure la no disponibilidad de espectro radioeléctrico atribuido a este servicio.

Articulo 40.- Otorgamiento de autorizaciones por Concurso Público y plazo para su realización

Las autorizaciones del servicio de radiodifusión se otorgan obligatoriamente mediante Concurso Público, cuando la cantidad de frecuencias o canales disponibles en una misma banda y localidad, es menor al número de solicitudes admitidas.

Asimismo, las nuevas autorizaciones para el servicio de radiodifusión por televisión se otorgarán por Concurso Público. Excepcionalmente, siempre que no hubiera restricciones de espectro, se podrá otorgar a pedido de parte, nuevas autorizaciones para la prestación del servicio de radiodifusión por televisión con tecnología analógica, cuando esta decisión promueva el desarrollo del servicio en áreas rurales, de preferente interés social o en zonas de frontera; de acuerdo a las condiciones, plazos y en las localidades que establezca el Ministerio.

En el mes de enero de cada año, la Dirección General de Autorizaciones en Telecomunicaciones elaborará un cronograma para la realización de por lo menos dos (2) Concursos Públicos anuales, dependiendo del número de localidades cuyas autorizaciones se otorgarán por dicho mecanismo.

(34) Reglamento Marco de Acceso a la Infraestructura de Transporte de Uso Público, Resolución de Presidencia del Consejo Directivo No. 014-2003-CD-OSITRAN

Artículo 3.- Definiciones

$(\ldots)$

x) Usuario intermedio

Es la persona natural o jurídica que utiliza la infraestructura de transporte de uso público para brindar servicios, de transporte o vinculados a esta actividad.

(35) Resolución de Presidencia del Consejo Directivo No. 014-2003-CD-OSITRAN

Artículo 7.- Concepto de Acceso. 


\section{Eduardo Quintana Sánchez y Lucia Villarán}

Este acceso puede darse mediante 3 modalidades excluyentes:

- Contrato de acceso acordado vía negociación directa;

- Contrato de acceso celebrado como consecuencia de una subasta convocada por el titular de la infraestructura; o,

- Mandato de acceso dictado por el regulador del sector ${ }^{(36)}$.

En términos simples, el procedimiento para determinar la modalidad de acceso a las Facilidades Esenciales se inicia con una solicitud de acceso del Usuario Intermedio, cuyos principales términos son publicados por el titular de la infraestructura para que en un plazo determinado cualquier otro interesado manifieste su intención de acceder a la misma Facilidad Esencial. Concluido dicho plazo, el titular de la infraestructura define si la disponibilidad de la Facilidad Esencial es suficiente para los que hayan manifestado interés en acceder a la misma o no. Si no hubiera disponibilidad suficiente, el acceso se otorga a través de una subasta que define al ganador o ganadores de la misma.

Los casos expuestos muestran la forma en que típicamente se manifiestan las regulaciones con efectos relativos sobre la entrada al mercado, esto es, limitaciones al ingreso como resultado de procesos de concurso (competencia por el mercado) que determinan un número reducido de agentes que pueden operar. Usualmente, esto ocurre cuando se presenta una situación de escasez de determinados bienes esenciales para poder operar en el mercado (por ejemplo, espectro radioeléctrico o facilidades esenciales de infraestructuras de transporte de uso público). Sin perjuicio de ello, también se pone de manifiesto que este tipo de regulación se utiliza para tratar de asegurar un uso racional de los recursos que no afecten a terceros (control de externalidades), como por ejemplo en la forma de asignación de espectro radioeléctrico para los servicios de telefonía e Internet móvil, que busca evitar problemas de interferencias indebidas entre servicios y entre operadores del mismo servicio.

\subsection{Restricciones al control sobre infraestructuras o recursos escasos}

Dentro del abanico de opciones de regulación de entrada también se pueden identificar medidas que no impiden la entrada al mercado pero limitan la capacidad de ciertas empresas de extender su control sobre recursos escasos o sobre infraestructuras, con el objetivo de evitar el acaparamiento o de diversificar a los agentes que actúan en el mercado. Así esta regulación funciona también como una restricción a la entrada, al impedir el crecimiento de ciertos agentes o su integración vertical. Algunos ejemplos ponen de manifiesto el funcionamiento de este tipo de medidas.

\footnotetext{
Se entiende por Acceso el derecho que tiene un usuario intermedio de utilizar una Facilidad Esencial como recurso necesario para brindar Servicios Esenciales que se integran a la Cadena Logística. En tal virtud, el presente Reglamento regula el fenómeno económico relativo a la insustituible utilización de las Facilidades Esenciales por parte de los usuarios intermedios.

(36) Resolución de Presidencia del Consejo Directivo No. 014-2003-CD-OSITRAN

Artículo 19.- "Formas de acceder a las Facilidades Esenciales.

Las formas de acceder a las Facilidades Esenciales administradas por las Entidades Prestadoras son las siguientes:

a) Mediante Contrato de Acceso celebrado como consecuencia de una negociación directa. El derecho de Acceso se otorgará mediante negociación directa, cuando la disponibilidad de infraestructura permita atender todas las solicitudes de Acceso declaradas procedentes. Se procederá de igual manera, si el número de bases entregadas o vendidas en un procedimiento de subasta, es menor o igual al número de espacios de que dispone la infraestructura.

b) Mediante Contrato de Acceso celebrado como consecuencia de una subasta convocada por la Entidad Prestadora. E derecho de Acceso se otorgará mediante el mecanismo de subasta si la disponibilidad de la Facilidad Esencial no permite atender todas las solicitudes declaradas procedentes, salvo que el contrato de concesión hubiera previsto un mecanismo diferente.

c) Mediante la emisión de un Mandato de Acceso que emita OSITRAN, en los supuestos a que se refiere el Artículo 44 en este Reglamento".
} 


\section{Regulación de Entrada: Experiencia peruana sobre prohibiciones y restricciones para el acceso al mercado Entry regulation: Peruvian experience on prohibitions and restrictions to the market access}

Un primer caso es el de la norma que impide el acaparamiento en los medios de comunicación masiva, específicamente la radio y televisión de señal abierta. Esta norma establece un límite máximo de tenencia del $30 \%$ de las frecuencias técnicamente disponibles en una misma banda de frecuencias del espectro radioeléctrico para la televisión, y de $20 \%$ de las frecuencias técnicamente disponibles en una misma banda de frecuencias del espectro radioeléctrico para la radio. De conformidad con la norma, ninguna persona natural o jurídica puede ser titular de frecuencias de televisión o radio superando esos límites, considerándose para efectos de computar la tenencia de las referidas frecuencias tanto las relaciones de parentesco entre personas naturales como las relaciones de vinculación por propiedad o gestión que puedan tener las personas jurídicas ${ }^{(37)}$. Esta prohibición se materializa al tramitar las solicitudes de autorización que puedan dar lugar al supuesto prohibido.

Otro caso vinculado también al espectro radioeléctrico se presenta en los servicios de telecomunicaciones que utilizan ese recurso escaso. El marco legal establece que el MTC puede disponer límites a la asignación de espectro con el fin de evitar el acaparamiento y garantizar la competencia, siendo ellos de obligatorio cumplimiento para las empresas operadoras ${ }^{(38)}$. Estos límites han sido fijados en particular para los servicios de telefonía e Internet móvil, señalándose primero que el tope que se puede tener de espectro es de $60 \mathrm{MHz}$ en todas las bandas atribuidas a esos servicios y de $25 \mathrm{MHz}$ en la banda de $800 \mathrm{MHz}^{(39)}$. Luego, el tope de $60 \mathrm{MHz}$ se ha ido ampliando teniendo en consideración la necesidad de mayores capacidades de transporte de señales para que los operadores puedan cursar comunicaciones con mayores contenidos (video), específicamente para bandas que permiten tecnologías de cuarta generación (4G).

(37) Ley de Radio y Televisión, Ley 28278

Artículo 22.- Normas para la titularidad de autorizaciones

La radio y la televisión no pueden ser objeto de exclusividad, monopolio ni acaparamiento, directa ni indirectamente, por parte del Estado ni de particulares.

Se considerará acaparamiento para efectos de la presente Ley el que una persona natural o jurídica, sea titular de más del treinta por ciento $(30 \%)$ de las frecuencias disponibles técnicamente, asignadas o no, en una misma banda de frecuencia dentro de una misma localidad, para la radiodifusión televisiva y veinte por ciento $(20 \%)$ para la radiodifusión sonora.

Para efectos del cómputo del número de frecuencias, se considera como una sola persona jurídica, a dos o más personas jurídicas que tengan como accionista, asociado, director o gerente común a una misma persona natural o pariente de esta dentro del segundo grado de consanguinidad.

(38) Lineamientos de Apertura del Mercado de Telecomunicaciones, Decreto Supremo No. 020-98-MTC, modificado por el Decreto Supremo No. 009-2006-MTC

27. Cuando una concesión involucra el uso del espectro, se requiere que los operadores del servicio cumplan meas de uso del espectro radioeléctrico razonables y justificadas establecidas por el MTC ya que su uso restringe a otro operador potencial de ofrecer servicios usando ese espectro. Por lo tanto, de no cumplir con las metas de uso de espectro radioeléctrico, el operador perderá el espectro radioeléctrico asignado, el cual podrá ser otorgado a otro operador y de ser el caso, la concesión otorgada en los casos expresamente previstos en el contrato.

Asimismo, los operadores del servicio deberán cumplir con los topes a la asignación del espectro radioeléctrico u otros mecanismos que apruebe el MTC a fin de evitar el acaparamiento de dicho recurso, en los casos y condiciones que se fijen para tal efecto.

85-A. La asignación y utilización eficiente del espectro radioeléctrico como herramienta para garantizar la competencia en la prestación de los servicios públicos de telecomunicaciones, se garantizará, también, mediante el establecimiento de topes a la asignación de este recurso y de otros mecanismos que apruebe el MTC, evitando así el acaparamiento de frecuencias que puedan limitar y/o impedir el acceso al mercado de potenciales competidores.

(39) Decreto Supremo No. 011-2005-MTC

Artículo 1.- Fijar como tope en sesenta (60) $\mathrm{MHz}$ las asignaciones de espectro para los servicios troncalizado, telefonía móvil y servicio de comunicaciones personales, como asignación total por concesionario. Ningún concesionario podrá tener mayor espectro a dicho tope. 


\section{Eduardo Quintana Sánchez y Lucia Villarán}

Adicionalmente a lo anterior, también se han establecido medidas explícitas para que ciertas empresas que ya controlan una determinada porción del espectro radioeléctrico queden impedidas de participar en nuevos concursos públicos de asignación de espectro y como resultado de los cuales podrían llegar a controlar una porción mayor de este recurso de resultar ganadores. Estas disposiciones han tenido el claro objetivo de garantizar la competencia y de evitar que se consoliden posiciones de dominio en el mercado. A modo de ejemplo, en el año 2009 se estableció que los operadores de diversos servicios de telecomunicaciones (o sus vinculadas) que ya contaban con una asignación de espectro para atender Lima y Callao, no podían participar en el concurso para la asignación de las frecuencias de las Bandas 2668 - $2692 \mathrm{MHz}$ y 2668 - $2690 \mathrm{MHz}$. Asimismo, se estableció que los operadores de telefonía móvil que ya estaban en operación, y que por ende ya contaban con una asignación de espectro radioeléctrico, no podían participar en el concurso para la asignación de $25 \mathrm{MHz}$ de la Banda C de 1900 $\mathrm{MHz}^{(40)}$

Un tercer caso de restricciones al crecimiento de una empresa está vinculado con infraestructura portuaria. En el año 2010, se emitió una norma que dispuso que en aquellos puertos en los que se prevea la participación de más de un administrador portuario, pues quedaba impedido de participar en el concurso para la entrega en administración del terminal portuario correspondiente el concesionario que ya estuviera administrando infraestructura portuaria de titularidad y uso público en el mismo puerto ${ }^{(41)}$. Esta limitación fue aplicada a DP World Callao, como concesionario del

Artículo 2.- Las bandas $824-849 \mathrm{MHz}$ y $869-894 \mathrm{MHZ}$ se distribuyen de la siguiente manera:

(...).

En ningún caso, un concesionario podrá ser titular de las dos bandas A y B señaladas anteriormente. En consecuencia, ningún operador puede tener más de $25 \mathrm{MHz}$ en las bandas indicadas.

(40) Decreto Supremo No. 020-2009-MTC

Artículo 1.- Los concesionarios de servicios públicos de telefonía fija, telefonía móvil, servicios de comunicaciones personales, troncalizado, sistema de distribución multicanal multipunto (MMDS) y/o portador local que cuenten con asignación de espectro radioeléctrico que incluya a la provincia de Lima y la Provincia Constitucional del Callao para la prestación de sus servicios, no podrán participar en el concurso público para la asignación de las Bandas 2668 - 2692 MHz y 2668 - 2690 MHz señaladas en la Resolución Ministerial No. 660-2007-MTC/03.

Esta restricción se aplica a toda persona natural o jurídica vinculada a los concesionarios antes señalados, conforme a las normas especiales sobre vinculación y grupo económico aprobadas por Resolución SBS No. 445-2000, Resolución CONASEV No. 090-2005-EF/94.10 y Resolución CONASEV No. 005-2006-EF/94.10.

Artículo 2.- Los concesionarios de servicios públicos de telefonía móvil, servicios de comunicaciones personales y troncalizado, no podrán participar en el concurso público para la asignación de $25 \mathrm{MHz}$ de la Banda C de $1900 \mathrm{MHz}$ a que se refiere la Resolución Ministerial No. 405-2008-MTC/03.

Esta restricción se aplica a toda persona natural o jurídica vinculada a los concesionarios antes señalados, conforme a las normas especiales sobre vinculación y grupo económico aprobadas por Resolución SBS No. 445-2000, Resolución CONASEV No. 090-2005-EF/94.10 y Resolución CONASEV No. 005-2006-EF/94.10.

(41) Decreto Supremo que establece medidas para facilitar y fomentar la libre competencia en la prestación de los servicios portuarios - Decreto Supremo No. 033-2010-MTC

Artículo 1.- Establecen condiciones para facilitar y fomentar la libre competencia en la prestación de servicios portuarios

Para asegurar la competencia en la prestación de los servicios portuarios, en el caso de los puertos donde se prevea la participación de más de un administrador portuario, no podrá participar en los procesos de selección destinados a la entrega en administración del terminal portuario correspondiente, el administrador portuario privado que tenga vínculo contractual con el Estado para administrar infraestructura portuaria de titularidad y uso público en el mismo puerto.

Esta restricción alcanza a toda persona natural o jurídica vinculada al referido administrador portuario, conforme las normas especiales sobre vinculación y grupo económico aprobadas mediante Resolución SBS No. 445-2000 y Resolución CONASEV No. 090-2005-EF/94.10. 


\section{Regulación de Entrada: Experiencia peruana sobre prohibiciones y restricciones para el acceso al mercado Entry regulation: Peruvian experience on prohibitions and restrictions to the market access}

Muelle Sur del terminal portuario del Callao, en el concurso para otorgar la concesión del Muelle Norte del terminal portuario del Callao ${ }^{(42)}$.

El sustento de la referida norma fue que de acuerdo con los Lineamientos de la Política Nacional del Transporte debía promoverse la competencia en el mercado de las actividades de servicios portuarios y, además, que era importante garantizar la competencia en el mercado de los puertos en la medida que la presencia de más de un operador portuario generaba una mayor oferta de servicios con menores costos y mayor calidad para los usuarios. Cabe mencionar que si bien la normativa general del sector portuario establece la promoción de competencia como lineamiento de política en este sector, a diferencia de la regla expresa del marco legal del sector telecomunicaciones, la regulación portuaria no otorga una habilitación específica para que la autoridad del sector establezca limitaciones a la participación privada en el mercado de servicios portuarios ${ }^{(43)}$.

Sin perjuicio de los sustentos válidos para introducir medidas que establecen restricciones para la entrada de agentes al mercado (número limitado) o que impiden la expansión de ciertos agentes que ya están operando, existen casos en los cuales las restricciones generadas a través del marco legal o decisiones de autoridades no tienen fundamento y producen efectos no deseados. El siguiente caso es muestra de ello.

\subsection{Restricciones de entrada sin sustento en el servicio de examen de manejo de autos $^{(44)}$}

La obtención de una licencia para conducir vehículos automotores requiere aprobar un examen práctico de manejo de dichos vehículos. Este examen se debía aprobar ante una entidad del Estado hasta la década de los noventa. Posteriormente, el marco legal permitió que particulares debidamente autorizados por el MTC instalen centros de evaluación para prestar el servicio de examen de manejo a todos los interesados. En virtud de ello, se han establecido diversos centros autorizados para tomar el referido examen en distintas jurisdicciones del país.

En el caso de la Región Lima, el Touring Automóvil Club del Perú (Touring) es el único centro de evaluación autorizado por el MTC para tomar el examen de manejo desde hace más de 20 años. Esta situación puede resultar extraña si se considera que no existen limitaciones de tipo estructural que la expliquen (costos hundidos específicos requeridos para dicha actividad).

(42) El Decreto Supremo No. 033-2010-MTC fue cuestionado por la empresa DP World Callao mediante la interposición de una acción de amparo contra el Ministerio de Transportes y Comunicaciones cuyo sustento fue la inconstitucionalidad de este dispositivo por restringir el derecho a la libre iniciativa privada. Asimismo, DP World Callao consideró que esta norma tenía carácter auto aplicativo por lo que restringía en forma directa su participación en el concurso público para la entrega en concesión del Muelle Norte. De otro lado, DP World Callao también interpuso una demanda arbitral contra el Estado Peruano ante el Centro Internacional de Arreglo de Diferencias Relativas a Inversiones - CIADI por haberle impedido participar en el concurso público para la concesión del Muelle Norte.

(43) Téngase en cuenta, por ejemplo, lo que señala la Ley del Sistema Portuario Nacional - Ley 27943

Artículo 3.- Lineamientos de la Política Portuaria Nacional

El Estado fomenta, regula y supervisa, a través de los organismos competentes establecidos por la presente Ley, las actividades y los servicios portuarios, con sujeción a los lineamientos de política portuaria que ella establece. Constituyen lineamientos esenciales de la Política Portuaria Nacional:

$(\ldots)$

7. La promoción del libre acceso, la leal competencia y libre concurrencia al mercado de los servicios portuarios.

En la misma línea de razonamiento, la Política Nacional del Sector Transportes, aprobada por Resolución Ministerial No. 817-2006-MTC/09, establece como estrategia la necesidad de promover la competencia efectiva en el mercado de servicios portuarios.

(44) Esta sección se basa en un estudio elaborado por el INDECOPI. Véase Comisión de Defensa de la Libre Competencia del INDECOPI. Abogacía de la competencia en el mercado del servicio de examen práctico de manejo en la Región Lima. Diciembre 2014. 


\section{Eduardo Quintana Sánchez y Lucia Villarán}

EI INDECOPI verificó que el Touring tenía la condición de proveedor único del servicio en Lima en virtud de un convenio suscrito con el MTC que ha sido renovado en 17 oportunidades. Asimismo, identificó que aun cuando no existe una exclusividad legal en favor del Touring para brindar dicho servicio, el MTC no había suscrito ningún convenio adicional para permitir el ingreso de otro operador privado para la prestación del mismo. Más aún, el INDECOPI verificó que el MTC había negado en varias oportunidades solicitudes de otros agentes privados (universidades) interesados en obtener una autorización como centro de evaluación para Lima, aduciendo la falta de un procedimiento que regule la entrada para la prestación de este servicio.

De acuerdo con el marco legal, le concierne al MTC adoptar las acciones que correspondan para permitir el ingreso de nuevos centros de evaluación que brinden este servicio, mediante la creación de procedimientos que posibiliten la entrada y operatividad de nuevos agentes, así como a través de la realización de concursos públicos para su autorización ${ }^{(45)}$. Sin embargo, el INDECOPI consideró que el MTC había dejado de tomar acción para implementar mecanismos de competencia por el mercado que posibiliten el ingreso de nuevos agentes o, en su caso, para establecer un procedimiento de aprobación previa para otorgar nuevas autorizaciones ${ }^{(46)}$.

De este modo, decisiones gubernamentales (negativa de autorizaciones adicionales) o la ausencia de ellas (inactividad para crear los procedimientos requeridos) han llevado a que se instaure una exclusividad de facto en el servicio de examen de manejo en la Región Lima, que no tiene mayor explicación puesto que en otras jurisdicciones se ha instalado más de un centro de evaluación y, en algunas de ellas, el costo del examen resulta menor que el cobrado en Lima (por ejemplo, en el Callao).
Los efectos indeseados al utilizar indebidamente un sistema de autorización para realizar determinada actividad comercial saltan a la vista.

\section{Conclusiones}

Como se ha visto, la regulación de entrada otorga la posibilidad de proveer un determinado bien o servicio a un solo agente económico o a un grupo reducido de agentes en cierto mercado. Con ello se genera un derecho exclusivo en favor de uno o pocos agentes, impidiéndose por vía regulatoria que terceros realicen la misma actividad y, por ende, protegiéndolos de mayor competencia. Según se limite total o parcialmente el ingreso de otros agentes a realizar la misma actividad económica, esta regulación puede calificarse como con efectos absolutos o relativos sobre la entrada, respectivamente.

Diversas razones pueden sustentar el uso de regulación de entrada, tales como el equilibrio de monopolios naturales, el aseguramiento de obligaciones de interés público, el control del acceso y uso de recursos escasos así como de externalidades, e incluso el control de la expansión del poder de mercado. Sin embargo, la regulación de entrada puede tener efectos negativos importantes, vinculados con la restricción de la competencia, la eliminación o reducción de opciones de elección de los consumidores, la necesidad de introducir nuevas medidas de regulación (precios,

(45) Al respecto, la Comisión planteó en términos generales lo siguiente: "La acción de las entidades públicas encargadas de autorizar el ingreso y supervisar el funcionamiento de los operadores del mercado es un factor determinante para incentivar o desalentar la competencia. Diversas autoridades y organismos internacionales han puesto énfasis en el rol activo que deben tener las autoridades para promover la competencia".

(46) En opinión de la Comisión: “(...) el artículo 21 del Reglamento admite la posibilidad que terceros puedan desempeñarse como Centros de Evaluación, bajo 'cualquiera de los mecanismos de promoción de la inversión privada o contratación pública previstos en las leyes nacionales'. Pese a esta previsión normativa, el MTC ha mostrado cierta inactividad para fomentar el ingreso de nuevos operadores". 


\section{Regulación de Entrada: Experiencia peruana sobre prohibiciones y restricciones para el acceso al mercado Entry regulation: Peruvian experience on prohibitions and restrictions to the market access}

calidades, etcétera), o el debilitamiento de los incentivos a la innovación.

Por ello, la legitimidad de la regulación de entrada depende sin duda de la justificación que la sustenta, así como del diseño que tenga, pues la necesidad de adoptarla debe ser manifiesta para considerar aceptables sus potenciales efectos negativos.

Dentro del marco legal peruano, existe un espacio para utilizar excepcionalmente la regulación con efectos absolutos sobre la entrada (prohibición o impedimento de ingreso de competidores), particularmente en los mercados de servicios públicos. Sin embargo, su utilización debe encontrarse debidamente sustentada por las características especiales de los mercados y, en lo posible, debe buscarse que tales prohibiciones o impedimentos puedan levantarse progresivamente (elementos de temporalidad o de ámbito territorial de aplicación).

Además, la posibilidad de establecer regulación con efectos relativos sobre la entrada de competidores al mercado (limitaciones al número de agentes habilitados o sistemas de control previo), tampoco es irrestricta. Más bien necesita tener fundamento objetivo y restringirse a los ámbitos permitidos por el marco legal, siendo uno de ellos el de las actividades de servicios públicos que se realizan mediante concesiones, caso en el cual las normas sectoriales pueden establecer ciertas limitaciones al régimen general de libre entrada al mercado.

Los casos particulares explicados demuestran varios elementos típicos de la regulación con efectos absolutos sobre la entrada. La misma funciona usualmente prohibiendo o impidiendo el ingreso de nuevos competidores a través de derechos exclusivos de explotación de infraestructuras y prestación de servicios públicos. Es usual el establecimiento de este tipo de regulación en industrias de redes con características de monopolio natural, en los cuales existen obligaciones de realizar importantes inversiones en infraestructuras con carácter de costo hundido (típicamente monopolios naturales). No es extraño que los operadores en cuyo favor se impone la regulación de entrada asuman obligaciones de atención a todos los usuarios dentro de la zona de concesión, y que sus actividades puedan ser proclives al descreme del mercado.
Adicionalmente, la regulación de entrada puede modularse en términos geográficos y temporales, con el fin de asegurar a los concesionarios períodos adecuados para la maduración de sus inversiones y para el cumplimiento de mandatos específicos y particulares de cada industria (como en el caso del rebalanceo tarifario en telefonía fija y de larga distancia), pero también con la lógica de desmantelar progresivamente monopolios allí donde las características del mercado lo permitan.

Sin embargo, la regulación con efectos absolutos sobre la entrada, que no tiene un adecuado sustento, tiene un claro impacto negativo en las condiciones de competencia y el bienestar de los consumidores 0 usuarios.

Finalmente, también se han presentado casos que demuestran que las regulaciones con efectos relativos sobre la entrada al mercado se materializan a través de limitaciones al ingreso como resultado de procesos de concurso (competencia por el mercado) que determinan un número reducido de agentes que pueden operar. Usualmente, esto ocurre cuando se presenta una situación de escasez de determinados bienes esenciales para poder operar en el mercado. Sin perjuicio de ello, este tipo de regulación se utiliza también para tratar de asegurar un uso racional de los recursos que no afecten a terceros (control de externalidades).

Dentro del abanico de opciones de regulación de entrada, también se pueden identificar medidas que no impiden la entrada al mercado pero limitan la capacidad de ciertas empresas de extender su control sobre recursos escasos o sobre infraestructuras, con el objetivo de evitar el acaparamiento o de diversificar a los agentes que actúan en el mercado. Así esta regulación funciona también como una restricción a la entrada, al impedir el 


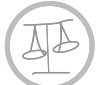

\section{Eduardo Quintana Sánchez y Lucia Villarán}

crecimiento de ciertos agentes o su integración vertical.

\section{Referencias Bibliográficas}

Ogus, Anthony. 2004. Regulation: Legal Form and economic theory. Oxford: Hart publishing.
OSIPTEL. 1998. Memoria Anual 1997, los Usuarios y las Telecomunicaciones. Lima, Mercados Consultora y Publicaciones. 1999. Memoria Anual 1998, Cinco Años en el Mercado de las Telecomunicaciones. Lima, Mercados Consultora y Publicaciones. 